\title{
Resilience Assessment of Semnan, Iran, in the Face of an Earthquake
}

\author{
Mozafar Mohammadkhani $^{1} \mathbb{D}$, Zeinab Karkehabadi $^{2} \mathbb{D}$, Abbas $^{\text {Arghan }^{2}}{ }^{\mathbb{D}}$
}

Date of submission: Aug 202020 Date of acceptance: Sep 21, 2020

\section{Original Article}

\begin{abstract}
INTRODUCTION: Resilience is considered a way of strengthening societies using their capacities which can be defined as the ability of systems to adapt to changes without collapsing at the incidence of disasters. To understand resilience and the way it is analyzed at the community level, it is necessary to study the society's current condition and policies, as well as the measures adopted to reduce risk and how the risks in society are dealt with. This study aimed to assess the resilience of urban communities in the face of an earthquake.

METHODS: This descriptive-analytical study was conducted using a questionnaire to collect the required data in Semnan, Iran, in 2019. The statistical population of this study $(n=384)$ consisted of the citizens of Semnan selected using the Cochran formula and random sampling method. The collected data were analyzed in SPSS software (version 23) using mean and percentage for descriptive analysis and Pearson correlation coefficient and one-sample t-test for inferential statistical tests.

FINDINGS: Based on the results, the sociocultural, infrastructural-physical, economic, and institutional-organizational dimensions showed the current condition of resilience in Semnan with the mean scores obtained as $2.59,3.05,2.17$, and 2.56 , respectively. It was also revealed that resilience had a significant relationship with age, education, income, accommodation ownership, employment, calculated by the Pearson correlation coefficient $(\mathrm{P}$-value $=0.99)$.

CONCLUSION: The mean scores and significance level of the economic resilience in Semnan revealed that this city lacked economic resilience. In this regard, it can be noted that residents' lack of skills in other fields and jobs, lack of possessions outside the city, the vulnerability of residents' properties and assets, level of economic poverty in the city, citizens' limited financial ability to participate economically, and low level of household savings to compensate for earthquake damage have made returning to pre-crisis conditions highly difficult for citizens, and consequently, they cannot be economically resilient.
\end{abstract}

Keywords: Earthquake; Natural Disasters; Resilience; Semnan; Vulnerability.

How to cite this article: Mohammadkhani M, Karkehabadi Z, Arghan A. Resilience Assessment of Semnan, Iran, in the Face of an Earthquake. Sci J Rescue Relief 2020; 12(3): 217-226.

\section{Introduction}

O ountries are increasingly transforming into urbanization around the world (1). According to the United Nations, it is estimated that about $80 \%$ of the world's population will be living in cities by 2050 (2-4). Regarding this, urban areas will become the main target of numerous potential (natural) disasters. Therefore, one of the responsibilities of urban planners is determined as trying to make the city a calm, safe healthy environment that protects the health of its citizens $(5,4)$. In this respect, reducing the risk of disasters is of particular importance that it needs to be considered in the national policies of each country, which leads to the creation of favorable conditions for effective and efficient risk reduction at various levels of society (6).

Natural hazards have the potential to become devastating and destructive disasters for human communities in the absence of risk mitigation systems $(7,8)$. Natural disasters are considered major challenges in achieving the sustainable development of human societies. The recognition

1-PhD Student, Geography and Urban Planning, Islamic Azad University of Semnan Branch, Semnan, Iran

2-Associate Professor, Department of Geography and Urban Planning, Islamic Azad University of Semnan Branch, Semnan, Iran Correspondence to: Zeinab Karkehabadi, Email: z.karkeabadi@yahoo.com 
of methods accomplishing this sustainability through various models of vulnerability reduction has been included in crisis management planning. Moreover, it has gained suitable attention in the national policies of each country to create favorable conditions for efficient and effective reduction of risks at different levels of disaster management (6).

In recent years, a new concept called resilience has been introduced in the crisis management domain. In this regard, explaining the relationship between resilience and natural disasters (e.g., earthquakes) is defined as how the capacities of societies in social, economic, organizational, political, and executive sectors affect the increase of resilience and understanding the dimensions of resilience in the society (9).

The notion of resilience had its roots in physics and mathematics and is used to describe the ability of a substance or system to return to equilibrium after displacement (10). This concept, introduced by Holling (referred to as the father of resilience) as a descriptive term in ecology in 1973 (11), has been widely used variously influencing different scientific fields, such as disaster management, psychology, and ecology (10).

Today, resilience is used in various domains, especially in disaster management. The increasing trend of paying attention to what has affected different societies has led them to find ways that help them and strengthen their power (12). As a result, it is necessary to study the dimensions and components of resilience in urban communities.

Leon et al. (2014) conducted a study to investigate the role of urban morphology in creating rapid resilience in the face of a tsunami. To this end, initially, based on the specific earthquake scenario, the flood-prone areas were determined and, subsequently, three different evacuation zones were identified. They presented the necessary measures adopted to improve the urban morphology in three groups, namely 1) creation or improvement of safe vertical or horizontal assembly areas, 2) improvement of the road networks condition, and 3) management of possible obstacles for the safe evacuation of the proposed paths. Eventually, they developed a factor-based computer model to determine and quantify the effects of the proposed reforms in increasing resilience. The results of this study were indicative of a significant increase in evacuees' security and evacuation procedure pace due to the implementation of proposed reforms (10).
Esmaeelzadeh et al., in their book titled "Theoretical Foundations in Urban Studies", discussed the most important urban issues in Iran. In two chapters of this book, namely urban crisis management and urban resilience to disasters and urban management in Iran (chapters 13 and 14, respectively), the key and basic concepts of crisis management and urban resilience are examined from the normative approach of "What it should be" and the positive approach of "What it is". Furthermore, the basic attitudes of crisis management and the principles and requirements of urban resilience in Iran are explained from the perspective of legal responsibilities and missions and current functions. Additionally, the strategies and measures that can be adopted to reduce the impact of disasters in cities and reach the concept of a safe, resilient, and prepared city (13).

Darban Astaneh and Heraini, in their research, performed a spatial analysis on the social and economic resilience of local communities against earthquakes in the Aftab district of Tehran, Iran . According to the findings of the mentioned study, only the indicator of employment and income conditions with a mean of 3.41 was higher than the resilience level. Moreover, demographic characteristics and awareness and knowledge about natural disasters were at a moderate level of resilience, while the indicators of social ties and collaborations and financial compensation capability were lower than the average level of resilience (14).

Semnan is one of the cities in Semnan Province located in the center of Semnan city. According to Iran's population and housing census in 2016, the population of Semnan was estimated at 185,129 people (equal to 49,124 households). Based on these results, 94,411 and 90,817 of cases were males and females, respectively. In 2016, based on the results of the labor force survey program, the economic participation and unemployment rates of the province were obtained as 38.9 and 8.6, which were 38.3 and 8.4 in the previous year, respectively. The employment-to-population ratio (number of employees per 100 population) in this age group was calculated at $35.6 \%$ and $35.1 \%$ in 2016 and 2015 , respectively. The results of this program showed that in 2016, about $34 \%, 14.9 \%$, and $50.9 \%$ of employees were employed in industry, agriculture, and service sectors, respectively (15).

Several factors have resulted in the vulnerability 
of Semnan city against natural disasters, such as earthquakes, leading to a lot of casualties and injuries and practically irreparable damages to the city. Among these factors the special geographical location (at the margin of the central desert) of Semnan, its increase in urban population, unprincipled growth and development, unsafe constructions in urban areas, dense textures highly dispersed, cultural economic differences in urban areas, tectonic features and location in a relatively high seismicity zone, the presence of faults in the vicinity of the city (Attari fault, Semnan), climatic change and continuous droughts, reduction of groundwater resources, non-implementation land management plans in locating urban facilities and lack of operational plans in the areas of disaster preparedness, and prevention and response in disaster management.

The present study was conducted in 2019 to investigate the effect of different resilience dimensions and indicators of Semnan and assess its resilience and urban sustainability in the face of natural hazards.

\section{Methods}

This descriptive-analytical study used a quantitative field research method to evaluate the socio-economic resilience of local communities in Semnan. The necessary data were collected using a questionnaire based on a survey method. The questionnaire investigates various constituent elements of society considering preparedness against earthquake, including social (awareness, knowledge, skills, and attitudes), economic (damage severity, damage compensation capability, and returning to appropriate conditions), institutional, organizational (institutional context, institutional relationships, institutional performance, and damage compensation capability) infrastructural-physical (critical infrastructures, buildings and constructions, transportation network, and public services). The statistical population of this study $(\mathrm{n}=384$ households) was all citizens living in Semnan selected by random sampling method.

The validity of the questionnaire was assessed using face validity with the opinions of the related individuals, and its reliability was confirmed using the Cronbach's alpha coefficient method $(\alpha=0.863)$ indicating the high coordination and reliability of the data. The collected data were analyzed in SPSS software (version 23) using mean and percentage for descriptive statistics and Pearson correlation coefficient and one-sample ttest for inferential statistics to examine the relationship between variables.

\section{Findings}

According to the findings, $55.7 \%$ of the samples were males, and $1.5 \%, 1 \%, 15.7 \%$, $34.6 \%$, and $41.7 \%$ of the cases had primary, middle school, high school, bachelor's degree, and master's degree or higher education level, respectively. Furthermore, it was revealed that $60.9 \%$ and $11.2 \%$ of the subjects were employed and unemployed, respectively. Considering possessing the accommodation, $66 \%$ of the samples were owners and $34 \%$ of them mortgaged and rented their living place. The general characteristics of the respondents obtained in five general variables, namely gender, education level, housing ownership, employment, and building materials and skeleton, are presented in Table 1.

Table 1. General characteristics of respondents

\begin{tabular}{|c|c|c|c|c|c|c|c|}
\hline \multicolumn{2}{|c|}{ Variable } & Frequency & Percentage & \multicolumn{2}{|r|}{ Variable } & Frequency & Percentage \\
\hline \multirow{2}{*}{ Gender } & Male & 214 & 55.7 & \multirow{5}{*}{ Occupation } & Employed & 234 & 60.9 \\
\hline & Female & 170 & 44.3 & & Un-employed & 43 & 11.2 \\
\hline \multirow{3}{*}{$\begin{array}{l}\text { Accommodation } \\
\text { ownership }\end{array}$} & Owner & 254 & 66 & & Housewife & 9 & 2.3 \\
\hline & Mortgaged and & 130 & 34 & & Student & 79 & 20.6 \\
\hline & rented & & & & Retired & 19 & 4.9 \\
\hline \multirow{6}{*}{$\begin{array}{l}\text { Building } \\
\text { materials and } \\
\text { skeleton }\end{array}$} & Concrete & 106 & 27.6 & \multirow{6}{*}{$\begin{array}{c}\text { Education } \\
\text { level }\end{array}$} & Primary school & 6 & 1.5 \\
\hline & Steel structure & 167 & 435 & & Middle school & 4 & 1 \\
\hline & Steer structure & 107 & & & High school & 60 & 15.7 \\
\hline & Iron and brick & 100 & 26 & & $\begin{array}{c}\text { Diploma and } \\
\text { associate degree }\end{array}$ & 23 & 6 \\
\hline & Wood and stone & 2 & 0.5 & & Bachelor & 132 & 34.6 \\
\hline & wood and stone & 2 & 0.5 & & Masters and & 159 & 41.7 \\
\hline
\end{tabular}


Table 2. Building quality and age

\begin{tabular}{|ccc|}
\hline Building age & Frequency & Percentage \\
\hline Newly built & 112 & 29.1 \\
Acceptable condition & 162 & 42.2 \\
Needs repair & 80 & 20.8 \\
Dilapidated & 30 & 7.9 \\
Total & 381 & 100 \\
\hline
\end{tabular}

\section{Building quality and age}

According to the research findings, $19.1 \%$ of the residential houses in this area were newly built, $37 \%$ were acceptable in terms of age and quality, $13.1 \%$ required repair, and $30.7 \%$ were dilapidated making them susceptible to (Table 2).

\section{Participation in crisis management sessions}

Based on the results, while only $10 \%$ of the respondents had received training, $90 \%$ of them did not attend crisis management sessions and lacked accurate and sufficient information about how to deal with the earthquake (Table 3).

\section{Sociocultural indicators}

A one-sample t-test was used to evaluate the level of sociocultural resilience of Semnan. Figure 1 and Table 4 summarize the information obtained from the respondents' opinions to the sociocultural indicators, which were different from each other. The awareness items included the evaluation of individual's knowledge about seismicity and earthquake risk in Semnan, community's awareness of how to react appropriately at the time of earthquake incidence, the ability of the
Table 3. Participation in crisis management sessions

\begin{tabular}{ccc|} 
Participation in crisis & Frequency & Percentage \\
management sessions & 40 & 10 \\
Yes & 345 & 90 \\
No & 384 & 100 \\
Total & \\
\hline
\end{tabular}

local community to adapt to the tensions and turmoil caused by an earthquake, the community's capacity and ability to reduce susceptibility to an earthquake, community's emergency response preparedness, local community's seismic risk perception and society's social attitude to seismic risk and causes of an earthquake in Semnan. According to the results, the mean scores of these items were obtained less than 3 and the p-value of less than 0.5 was estimated for all items, which was significant. This means that there was a $95 \%$ probability that these items were not in the desired condition.

It was also found out people's low ability to overcome critical situations and earthquakes, low skills of families (coping skills) in the incidence of an earthquake, limited physical access to health services across the city, low capacity and quality of health services at the community level, and insufficient coverage of social services (social welfare) at the community level has led to a low level of knowledge index. Moreover, the lack of social networks and citizen's indifference to local affairs have led to the non-participation of citizens in crisis management classes and workshops and their unfamiliarity with appropriate behavior

Table 4. Sociocultural indicator of resilience in Semnan

\begin{tabular}{|ccccccc|}
\hline Dimension & Indicator & Mean & P-value & T-value & Standard deviation & Standard error \\
& Awareness & 2.21 & 0.000 & -8.614 & 0.98 & 0.48 \\
Sociocultural & Knowledge & 1.98 & 0.000 & -17.432 & 0.42 & 0.86 \\
& Skills & 3.02 & 0.000 & 1.28 & 1.15 & 0.05 \\
& Attitude & 3.14 & 0.000 & 1.625 & 1.42 & 0.03 \\
\hline
\end{tabular}

Mean scores of sociocultural indicators

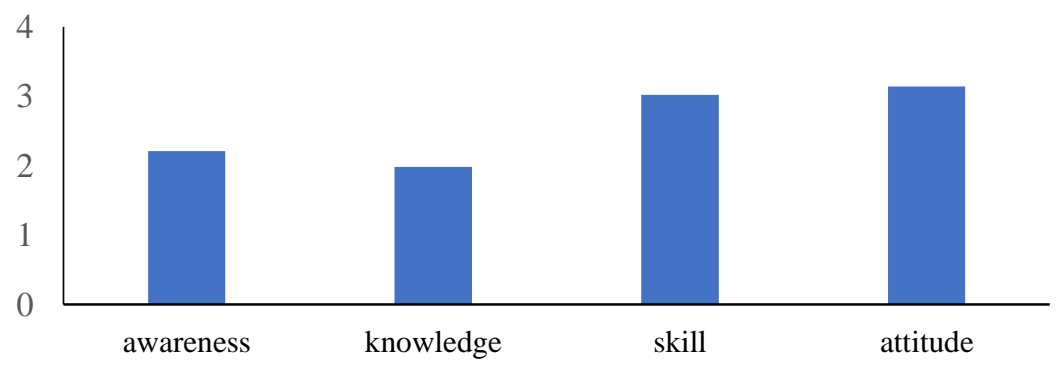

Figure 1. Mean scores of sociocultural indicators 
Table 5. Economic indicator of resilience in Semnan

\begin{tabular}{|ccccccc|} 
Dimension & Indicator & Mean & P-value & T-value & Standard deviation & Standard error \\
\multirow{3}{*}{ Economic } & Damage severity & 2.21 & 0.000 & -4.258 & 0.98 & 0.35 \\
& Damage compensation capability & 1.28 & 0.000 & -32.589 & 0.21 & 1.25 \\
& Returning to appropriate conditions & 3.02 & 0.000 & 3.190 & 1.14 & 0.11 \\
\hline
\end{tabular}

Mean scores of economic indicators

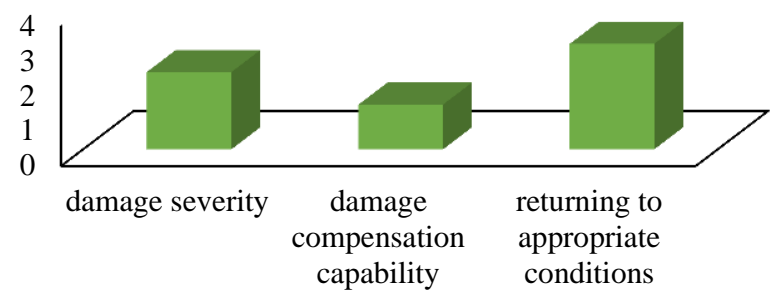

Figure 2. Mean scores of economic indicators

during an earthquake, which in turn, have reduced social resilience in Semnan.

Lack of citizen's participation after the incident can also be considered a key factor in returning the neighborhood to pre-crisis conditions. However, the items of cooperation with neighbors, trust in neighbors, attachment to the environment, and awareness of the resistance level of the living place showed relatively favorable mean scores and level of significance. Therefore, considering the results showing that most items in sociocultural indicators were in unacceptable conditions, it can be inferred that Semnan has a poor resilience regarding these indicators.

\section{Economic indicator}

The obtained data regarding the economic resilience index of Semnan are shown in Figure 2 and Table 5. Accordingly, the mean scores and their level of significance suggest a lack of economic resilience in this region. In this regard, it can be noted that residents' lack of skills in other fields and jobs, lack of possessions outside the city, vulnerability of residents' properties and assets, level of economic poverty in the city, citizens' limited financial ability to participate economically, and low level of household savings to compensate for earthquake damage have made returning to pre-crisis conditions highly difficult for citizens, and consequently, they cannot be economically resilient.

\section{Institutional-organizational indicator}

The institutional resilience index examines the institution's sense of responsibility toward crisis management and the people-institution bilateral relationship. The mean score and significance levels of this indicator in Semnan are summarized in Table 6 and Figure 3, showing an unfavorable condition. The mean score and p-value of all items

Table 6. Institutional-organizational indicators of resilience in Semnan

\begin{tabular}{|cc|ccccc|}
\hline Dimension & Indicator & Mean & P-value & T-value & Standard deviation & Standard error \\
\hline \multirow{2}{*}{ Institutional- } & Institutional context & 3.01 & 0.000 & 2.011 & -0.12 & 0.42 \\
organizational & Institutional relationship & 2.43 & 0.000 & -1.058 & -0.65 & 0.24 \\
& Institutional performance & 2.25 & 0.000 & -3.690 & -0.95 & 0.04 \\
\hline
\end{tabular}

Mean scores of institutional-organizational indicators

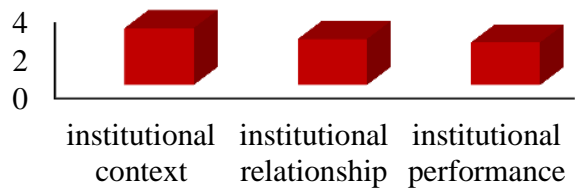

Figure 3. Mean scores of institutional-organizational indicators 
were obtained less than 3 and 0.5 , respectively, which was significant. Therefore, there is a $95 \%$ probability that Semnan is not resilient in terms of the institutional-organizational indicator. In this regard, the lack of volunteer groups related to crisis management, lack of participation in decision-making, irresponsibility in relevant organizations, and lack of relationship between people and municipality, city council, and other organizations have led to the lack of resiliency in this area. In case of the disaster incidence, the unfavorable condition of this indicator can be manifested in the inadequate number of relief workers, chaos in decision-making, lack of mutual trust between people and institutions, refusal of responsibilities by the relevant organizations, and, in general, the chaotic situation and the improper crisis management.

\section{Infrastructural-physical indicator}

Physical indicators can be considered the most important indicator in determining the resilience of a city, region, district, and similar areas. This indicator examines such items as the strength of buildings, spatial arrangement, the condition of vital arteries, and land-use system across a specific area. The condition of the physical indicator plays an important role in determining the resilience rate of an urban context. Due to the importance of this indicator, the data related to the physical resilience of Semnan are summarized in Table 7 and Figure 4. The results of this indicator were more satisfactory than those of other dimensions, showing that Semnan benefits from a better condition in terms of infrastructuralphysical resilience indicator.

\section{Summary of the current condition of resilience dimensions in Semnan}

The structure of urban resilience consisted of four dimensions, namely social, economic, institutional, and physical. In an ideal condition of a resilient city, it possesses a skillful local society with a dynamic and sustainable economy that is governed institutionally and executively in a collaborative manner. As a result of these superphysical factors, the city has been formed cohesively with no sign of wilting in any area. Lack of desirability in any of the dimensions of resiliency overshadows other dimensions and

Table 7. Infrastructural-physical indicator resilience in Semnan

\begin{tabular}{|ccccccc|}
\hline Dimension & Indicator & Mean & P-value & T-value & Standard deviation & Standard error \\
Infrastructural- & Critical infrastructures & 3.01 & 0.002 & 0.685 & 0.026 & 0.72 \\
physical & Buildings and constructions & 2.92 & 0.004 & -8.625 & 0.05 & 1.25 \\
& Transportation network & 3.20 & 0.000 & 2.641 & 0.62 & 0.02 \\
& Public services & 3.09 & 0.000 & 1.678 & 0.025 & 0.62 \\
\hline
\end{tabular}

Mean scores of infrastructural-physical indicators

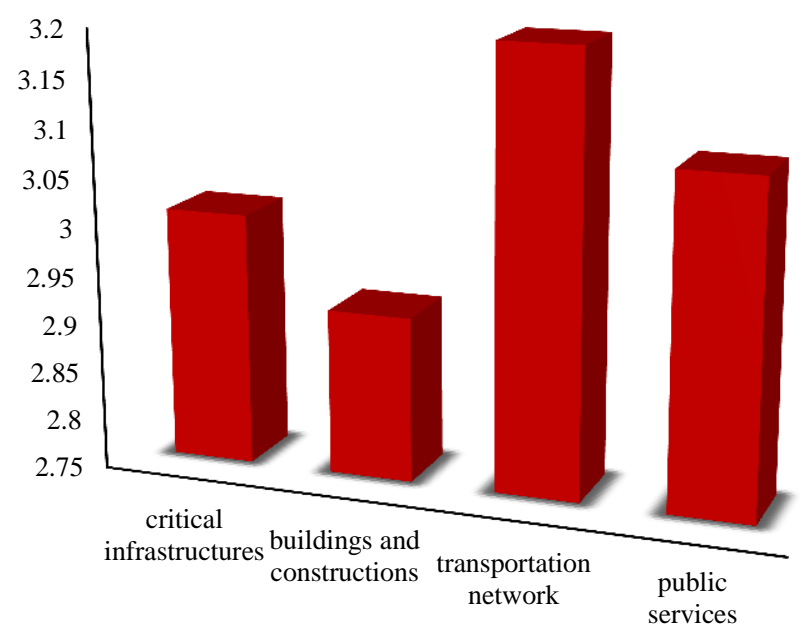

Figure 4. Mean scores of infrastructural-physical indicators 
Table 8. Results of Friedman test for dimensions of resilience in Semnan

\begin{tabular}{|ccc|}
\hline Indicator & Mean & Rank \\
Sociocultural & 2.59 & 2 \\
Infrastructural-physical & 3.05 & 1 \\
Economic & 2.17 & 4 \\
Institutional - Organizational & 2.56 & 3 \\
Chi-square & 367.68 & -- \\
P-value & 0.000 & -- \\
Total & 384 & -- \\
\hline
\end{tabular}

takes the city out of a stable state. The current conditions of the resilience dimensions of Semnan did not show a favorable state.

Institutional dimension has been revealed one of the weakest resiliency dimensions in this region due to the lack of crisis management institutions in the region, lack of trust between people and institutions, non-participation of people with city council and municipality, the underperformance of responsible organization to housing construction. Semnan has undergone an ecological process which caused families with an economic base to immigrate from the outer context of the city due to lack of infrastructure replaced with families with low economic and even with citizens from Pakistan and Afghanistan. Therefore, the most important factor causing the lack of economic resiliency among the residents of Semnan is the weakness of financial strength.

The social dimension was also not suitable in such indicators as the amount and level of coverage of social services (social welfare), the amount of people's participation in the crisis decision-making process, the amount of responsibility taken by relief organizations in crisis incidence. However, the physical dimension was found to be in a better condition due to the relatively good quality and strength of the buildings, the appropriate residential density, and, in general, proper condition of critical infrastructures and constructions, the transport network, and public services. Nevertheless, the non-implementation of the improvement and renovation plan of the urban worn-out textures in Semnan in terms of infrastructure network suffer from deficiencies. Additionally, it is difficult to access crisis management institutions, and the urban worn-out textures will increase in the next few years.

Table 8 tabulates the ranking of different studied dimensions in Semnan, showing that the physical dimension was in a better condition than the other dimensions. This ranking is based on a prerequisite which is determining the status of the indicators in relation to each other. It should be noted that the superiority of one indicator over the other does not indicate the desirability of that indicator. Therefore, as the results of the Friedman test shows in Table 8, the current conditions of resilience in Semnan were evaluated by the mean scores of $2.59,3.05,2.17$, and 2.56 for socio-cultural, infrastructural-physical, economic, and institutional-organizational dimensions, respectively (Figure 5).

\section{Analysis of the relationship between contextual variables and resilience}

In this part, the relationship of the social and economic characteristics of the respondents was investigated with sociocultural, infrastructuralphysical, economic and institutional-organizational resilience using statistical tests, and Spearman's rank correlation coefficient. To examine the relationship of the quantitative variables of research, including the degree of resilience in different dimensions, with qualitative categorical

Resilience degree of dimensions in Semnan

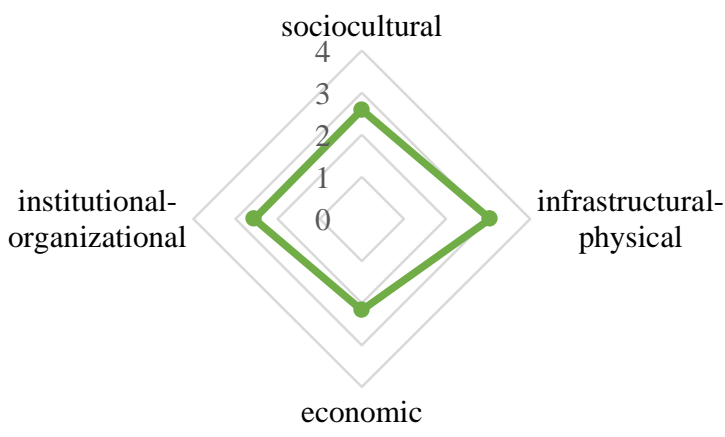

Figure 5. Resilience degree of dimensions in Semnan 
Table 9. Relationship between gender variable and resilience

\begin{tabular}{|ccccccc|}
\hline Group & Number & Mean & Standard deviation & T-value & Degrees of freedom & P-value \\
Male & 214 & 2.89 & 0.505 & -7.16 & 213 & 0.062 \\
Female & 170 & 2.78 & 0.370 & -8.59 & 169 & 0.062 \\
\hline
\end{tabular}

Table 10. Correlation between age with resilience

\begin{tabular}{|cccc|}
\hline Demographic characteristics & Number & Pearson correlation coefficient & P-value \\
\hline Age & 384 & -0.207 & 0.000 \\
Education level & 384 & 0.160 & 0.002 \\
Income & 384 & 0.92 & 0.000 \\
Accommodation ownership & 384 & 0.42 & 0.003 \\
Employment & 384 & 0.260 & 0.002 \\
\hline
\end{tabular}

variables of gender and employment status (employed, non-employed), one sample t-test and Spearman's rank correlation coefficient were used.

Moreover, the Pearson correlation coefficient was used to examine the relationship of quantitative variables, including the degree of socio-cultural, infrastructural-physical, economic, and institutional-organizational resilience, with qualitative nominal and ordinal variables, including head of household education level and accommodation ownership status. In order to compare males and females' opinion of resilience, the independent samples t-test was applied (Table 9). According to the obtained p-value, there was no significant difference between the gender variable and resilience.

The relationship of resilience with age, education, income, housing ownership, citizen employment was determined using the Pearson correlation coefficient (Table 10). According to this table, the Pearson correlation coefficient was estimated at -0.207 , and since the significance level was 0.000 , which was less than 0.05 , the obtained correlation coefficient was significant. In other words, there was a positive significant correlation between age and resilience (Pvalue $=0.9$ ).

Based on the results, the correlation between the education level and resilience was calculated at 0.160 and there was a significant relationship between these two variables $(\mathrm{P}$-value $=0.9)$. The Spearman correlation coefficient calculated for income was 0.92 , which was significant. This means that citizens' resilience degree showed a significant relationship with their income and housing ownership. Finally, the correlation coefficient was obtained as 0.160 between employment and resilience, a significant relationship was revealed between these two variables $(\mathrm{P}$-value $=0.9)$.

\section{Discussion and Conclusion}

The urban resilience approach is one of the most important and key approaches that ensure the survival of human settlements. Authorities and responsible officials can use this approach as a guide to make flexible decisions and adopt new policies for urban management. To build resilience in this domain, it is required to make an inter- and intra-cooperation and communication between organizations and authorities, adapt the management institution to the ecological scale of the needed resource, and prevent partisanship. Accordingly, this study was conducted to assess the resilience of urban communities in the face of earthquake risk in Semnan. The results of this study showed that in the sociocultural indicator, the condition of items in the social indicator was different.

The awareness items included the evaluation of individual's knowledge about seismicity and earthquake risk in Semnan, community's awareness of how to react appropriately at the time of earthquake incidence, the ability of the local community to adapt to the tensions and turmoil caused by an earthquake, the community's capacity and ability to reduce susceptibility to an earthquake, community's emergency response preparedness, local community's seismic risk perception and society's social attitude to seismic risk and causes of an earthquake in Semnan. According to the results, the mean scores of these items were obtained less than 3 and the p-value of less than 0.5 was estimated for all items, which was significant. This means that there was a $95 \%$ probability that these items were not in the desired condition.

It was also found out people's low ability to overcome critical situations and earthquakes, low skills of families (coping skills) in the incidence 
of an earthquake, limited physical access to health services across the city, low capacity and quality of health services at the community level, and insufficient coverage of social services (social welfare) at the community level has led to a low level of knowledge indicator. Moreover, the lack of social networks and citizen's indifference to local affairs have led to the non-participation of citizens in crisis management classes and workshops and their unfamiliarity with appropriate behavior during an earthquake, which in turn, have reduced social resilience in Semnan. Lack of citizen's participation after the incident can also be considered a key factor in returning the neighborhood to pre-crisis conditions. However, the items of cooperation with neighbors, trust in neighbors, attachment to the environment, and awareness of the resistance level of the living place showed relatively favorable mean scores and level of significance. Therefore, considering the results showing that most items in sociocultural indicators were in unacceptable conditions, it can be inferred that Semnan has a poor resilience regarding these indicators.

Considering the economic resilience indicator, the obtained mean scores and their level of significance suggest a lack of economic resilience in this region. In this regard, it can be noted that residents' lack of skills in other fields and jobs, lack of possessions outside the city, vulnerability of residents' properties and assets, level of economic poverty in the city, citizens' limited financial ability to participate economically, and low level of household savings to compensate for earthquake damage have made returning to precrisis conditions highly difficult for citizens, and consequently, they cannot be economically resilient.

The institutional resilience indicator in Semnan showed an unfavorable condition according to the obtained mean scores and their level of significance. The mean score and $\mathrm{p}$-value of all items were obtained less than 3 and 0.5 , respectively, which was significant. Therefore, there is a $95 \%$ probability that Semnan is not resilient in terms of the institutionalorganizational indicator. In this regard, the lack of volunteer groups related to crisis management, lack of participation in decision-making, irresponsibility in relevant organizations, and lack of relationship between people and municipality, city council, and other organizations have led to the lack of resiliency in this area. In case of the disaster incidence, the unfavorable condition of this indicator can be manifested in the inadequate number of relief workers, chaos in decisionmaking, lack of mutual trust between people and institutions, refusal of responsibilities by the relevant organizations, and, in general, the chaotic situation and the improper crisis management.

The results of infrastructural-physical indicators in Semnan showed that they were in a more satisfactory condition than the other dimensions. Finally, the current conditions of resilience in Semnan were evaluated by the Friedman test with the mean scores of $2.59,3.05,2.17$, and 2.56 for sociocultural, infrastructural-physical, economic, and institutional-organizational dimensions, respectively. It is worth mentioning that the results of the present study are consistent with those of the previous researches $(10,13,14)$ and are approved.

Gian Paolo Cimellaro mentioned the concept of resilience-based design as a part of the performance-based design and demonstrated some advanced applications to professionals. $\mathrm{He}$ presented various methods to evaluate resilience based on the latest scientific advances and revealed the differences between vulnerability, resilience, sustainability, and risk. Furthermore, he introduced the definitions and focused on the losses, recovery processes, downtime, and related probabilities, and subsequently, provided methods for analytical and exploratory evaluation. This author also introduced seven dimensions of society's resilience characteristics and the main and sub-components of each dimension. Additionally, he provided examples of its application in transportation and gas and electricity networks with emphasis on the physical dimension (infrastructure). He also considered the problem of correlation and chain reactions during the investigation and focused on different ways of improving disaster preparedness and engineering methods of reducing effects (16).

Gasparini et al. showed how the experience of disasters could be transformed into measures to promote sustainability, and how social networks are associated with susceptibility and sustainability. The mentioned research, employing analyzing the role and position of needs in collective and individual resilience, indicated how community interaction could improve the ratio of resilience decision-making processes and risk management in urban areas. Moreover, they 
introduced urban resilience as an essential aspect of the social sustainability of future cities and showed how citizen participation, along with advanced technologies, could play a key role in reducing the real-time risk incidence (17).

Regarding the economic resilience of Semnan, the obtained mean scores and p-values suggested the lack of economic resilience in this region. In this regard, it can be noted that residents' lack of skills in other fields and jobs, lack of possessions outside the city, vulnerability of residents' properties and assets, level of economic poverty in the city, citizens' limited financial ability to participate economically, and low level of household savings to compensate for earthquake damage have made returning to pre-crisis conditions highly difficult for citizens, and consequently, they cannot be economically resilient.

\section{Acknowledgments}

None

\section{Conflict of Interests}

The authors have no conflict of interest to declare.

\section{References}

1. Dutta V. War on the dream-how land use dynamics and peri-urban growth characteristics of a sprawling city devour the master plan and urban suitability? 13th Annual Global Development Conference, Budapest, Hungary; 2012.

2. Jha AK, Miner TW, Stanton-Geddes Z. Building urban resilience: principles, tools, and practice. New Hampshire: The World Bank; 2013.

3. Govindarajulu D. Strengthening institutional and financial mechanisms for building urban resilience in India. Int J Dis Risk Reduct 2020; 47: 101549.

4. Huck A, Monstadt J, Driessen P. Building urban and infrastructure resilience through connectivity: an institutional perspective on disaster risk management in Christchurch, New Zealand. Cities
2020; 98: 102573.

5. Soleimani Moghaddam M, Amir Ahmadi A, Kavian F. Investigating the role of land use planning in improving the seismic resilience of urban communities (Sabzevar case study). J Arid Regions Geographic Stud 2014; 5(17): 17-34 (In Persian)

6. Davis I, Ostovar Izadkhah Y. Building resilient urban communities. Open House Int 2006; 31(1): 11-21.

7. Zhou $\mathrm{H}$, Wan J, Jia $\mathrm{H}$. Resilience to natural hazards: a geographic perspective. Natural Hazards 2010; 53(1): 21-41.

8. Dunning KH. Building resilience to natural hazards through coastal governance: a case study of Hurricane Harvey recovery in Gulf of Mexico communities. Ecolog Econ 2020; 176: 106759.

9. Ilerisim. AKUT. Available at: URL: WWW.akut. org.tr/Default. Aspx? tabid=52; 2008.

10. León J, March A. Urban morphology as a tool for supporting tsunami rapid resilience: a case study of Talcahuano, Chile. Habitat Int 2014; 43: 250-62.

11. Kärrholm M, Nylund K, de la Fuente PP. Spatial resilience and urban planning: Addressing the interdependence of urban retail areas. Cities 2014; 36: 121-30.

12. Cross R. International federation of red cross and Red Crescent Societies. Personnel 2003; 1: 274-754.

13. Esmaeelzadeh $\mathrm{H}$. Theoretical foundations in urban studies with a look at the situation in Iran. Tehran: Teesa Publication; 2016. (In Persian)

14. Darban AA, Heraini M. Spatial analysis of socialeconomic resilience against earthquake in rural communities, case study: Aftab district, Tehran County. J Geography Plan 2019; 23(68): 91-111. (In Persian)

15. Statistical yearbook of Semnan province. Tehran: Statistical Center of Iran; 2016. (In Persian)

16. Cimellaro GP, Renschler C, Reinhorn AM, Arendt L. PEOPLES: a framework for evaluating resilience. J Struct Engin 2016; 142(10): 04016063.

17. Gasparini P, Manfredi G, Zschau J. Earthquake early warning as a tool for improving society's resilience and crisis response. Soil Dynamics Earthq Engin 2011; 31(2): 267-70. 